\begin{tabular}{|c|c|}
\hline Journal STAND: Sports and Development \\
unipa Sumalaya & http://jurnal.unipasby.ac.id/index.php/stand/about/submissions \\
\hline
\end{tabular}

\title{
ANALISIS INDIKATOR PERFORMA BOLA BASKET YANG MEMPENGARUHI SKOR PEMENANG PERTANDINGAN PELAJAR SEKOLAH MENENGAH
}

\author{
Fajar Hidayatullah \\ STKIP PGRI Bangkalan \\ fajar@stkippgri-bkl.ac.id
}

\begin{tabular}{l}
\hline Artikel Info \\
\hline Koresponden penulis: \\
Fajar Hidayatullah \\
Email. \\
fajar@stkippgri-bkl.ac.id \\
$\square$ Diterima 27 April 2020 \\
$\square$ Direview 13 Mei 2020 \\
$\square$ Disetujui 19 Mei 2020 \\
$\square$ Dipublikasi 27 Mei 2020
\end{tabular}

Kata Kunci:

Analisis, Indikator Performa,

Bola Basket, Pelajar, Sekolah

Menengab Pertama

Keywords:

Leg Power, Arm Muscle Strength, Underbasket Shoot

\begin{abstract}
Abstrak
Dalam sebuah pertandingan bola basket akan dicatat beberapa indikator pertandingan yang merupakan aspek menentukan bagi tim untuk memenangkan pertandingan. Cara paling sesuai dalam menganalisa permainan bola basket adalah mengamati statistik dari pertandingan bola basket. Pelaksanaan penelitian statistik pertandingan bola basket di tingkat pelajar putra Kabupaten Bangkalan diharapkan menjadi dasar evaluasi latihan pengembangan tim bagi pelatih maupun evaluasi pengembangan bola basket bagi PERBASI Kabupaten Bangkalan. Teknik pengambilan sampel yang digunakan adalah accidental random sampling dengan teknik analisis data menggunakan independent sample t-test serta uji normalitas menggunakan uji Kolmogorov-Smirnov serta dilengkapi uji homogenitas dengan uji Levane's test. Sebanyak 36 pertandingan bola basket antar pelajar putra yang berlangsung sepanjang tahun 2019 menjadi sampel dalam penelitian ini. Dari hasil penelitian ditemukan bahwa indikator performa turnover dan steal dalam statistik pertandingan memiliki perbedaan yang signifikan antara tim pemenang dan tim yang kalah. Tim pemenang memiliki rata-rata lebih sedikit melakukan turnover namun lebih banyak melakukan steal daripada tim kalah. Sedangkan tim kalah lebih banyak melakukan turnover dan lebih sedikit melakukan steal daripada tim pemenang. Secara umum hasil penelitian menunjukkan kemampuan penguasaan bola tim bola basket akan sangat menentukan untuk menghindari turnover pada pertandingan bola basket tingkat pelajar sekolah menengah putra sehingga akan meningkatkan persentase kemenangan.
\end{abstract}

\begin{abstract}
In a basketball game several indicators of the match will be noted which are the deciding aspects for the team to win the match. The most suitable way to analyze basketball games is to observe statistics from basketball matches. The implementation of statistical research on basketball matches at the level of male students of Bangkalan Regency is expected to be the basis for evaluating team development training for coaches and evaluating basketball development for PERBASI Bangkalan Regency. The sampling technique used was accidental random sampling with data analysis techniques using independent sample t-test and normality test using the Kolmogorov-Smirnov test and equipped with a homogeneity test with the Levane's test. A total of 36 basketball matches between male students which took place throughout 2019 were sampled in this study. From the results of the study found that the turnover and steal performance indicators in the match statistics have a significant difference between the winning team and the losing team. The winning team has on average fewer turnovers but steals more than the losing team. Whereas the losing team makes more turnovers and steals less than the winning team. In general, the results of the research show that the ability to control a basketball team will be crucial in avoiding turnover in a basketball game for high school students so that it will increase the winning percentage
\end{abstract}




\section{PENDAHULUAN}

Bola basket merupakan cabang olahraga yang memiliki karakteristik cukup kompleks. Dalam pertandingan bola basket beberapa indikator pertandingan dapat menjadi aspek yang menentukan sebuah tim untuk bisa memenangkan pertandingan. "The content of basketball game is determined by the diversity of technical elements and the variety of tactical tasks. The right balance of tactics and techniques is the factor of success" (Bazanov, 2007). Selain tujuan utama untuk mencetak angka lebih banyak daripada lawan, konten dari permainan bola basket dapat ditentukan dari beragam variasi strategi yang akan dijalankan, namun keseimbangan antara teknik dan strategi adalah sebuah faktor untuk mencapai kesuksesan dalam permainan bola basket. Kesuksesan dalam pertandingan bola basket diartikan sebagai kemenangan dimana tim yang mencetak poin lebih banyak keluar sebagai pemenangnya.

Studi tentang kebiasaan tim dalam sebuah pertandingan akan penting bagi setiap pelatih untuk menentukan kemampuan yang harus ditingkatkan oleh timnya maupun memahami kekuatan dari tim lain, sehingga selanjutnya dengan studi terkait tersebut pelatih memahami kekurangan ataupun kelebihan yang mereka miliki. Every coach's goal is to be in possession of information that could give him a tactical advantage over his opponents. This is the reason for increasing volume of research concentrated on the problem of automatic or semi-automatic game analysis using different sources of data, e.g (Fylaktakidou, Tsamourtzis, \& Zaggelidis, 2011). Dalam cabang olahraga bola basket terdapat banyak hal yang harus diamati mengingat bola basket merupakan cabang olahraga dengan sebuah karakteristik yang kompleks mulai dari kemampuan setiap individual hingga pada ciri permainan masingmasing tim yang berbeda antara satu maupun dengan lainnya. Cara paling sesuai dalam menganalisa karakteristik permainan bola basket adalah dengan mengamati statistik dari sebuah pertandingan bola basket. The study of basketball game-related statistics in competition has been used to identify variables that can distinguish between successful teams and players, which can lead to better sport results (Ibanez, Garcia, Feu, Lorenzo, \& Sampaio, 2009).

Dengan melakukan penelitian terkait statistik pertandingan bola basket di tingkat pelajar Kabupaten Bangkalan harapannya dapat menjadi dasar evaluasi latihan tim bagi pelatih dan evaluasi pengembangan bola basket secara umum bagi PERBASI Kabupaten Bangkalan. Hal ini sangat memungkinkan karena dengan mencermati statistik pertandingan bola basket antar pelajar akan sangat membantu mengukur karakter tim pemenang bola basket di Kabupaten Bangkalan. Saat ini belum ada peneliti sebelumnya yang membahas tentang 


\begin{tabular}{|c|c|}
\hline Journal STAND: Sports and Development \\
unttp://jurnal.unipasby.ac.id/index.php/stand/about/submissions \\
jurnal.stand@unipasby.ac.id
\end{tabular}

statistik pertandingan bola basket di Kabupaten Bangkalan sehingga dengan dilaksanakannya penelitian ini dapat menjadi jalan baru untuk mengembangkan bola basket Kabupaten Bangkalan khususnya pada kategori tim bola basket putra yang saat ini masih jauh tertinggal daripada daerah lainnya.

\section{KAJIAN LITERATUR DAN PEGEMBANGAN HIPOTESIS (JIKA ADA)}

Pada penelitian terdahulu telah ditemukan kesimpulan bahwa variabel yang memiliki hubungan dengan tembakan akan sangat mempengaruhi kemenangan dari sebuah tim. The victorious teams had more free throws made, field goals made (2- and 3-point field goal shots) and executed more defensive rebounds (Trninic, Dizdar, \& Luksic, 2002). Selain itu, kemampuan rebound tim juga nampaknya mendukung pengaruh permainan selain keberhasilan tembakan. Dalam hal ini kemampuan defensive rebound menjadi faktor yang paling utama karena dengan kemampuan defensive rebound yang lebih baik daripada lawan akan mengurangi peluang lawan untuk memperoleh kesempatan kedua saat melakukan penyerangan.

Hal ini juga serupa dengan kesimpulan ibanez dkk dimana dalam penelitiannya menyimpulkan bahwa tim pemenang pertandingan bola basket memiliki kemampuan menembak yang lebih baik daripada lawannya.
Kemampuan menembak yang lebih baik ini tentunya dari daerah 2 angka maupun daerah 3 angka. The results from the three-point field goals in the third game suggested that winning teams were able to shoot better from longer distances and this could be the result of exhibiting higher conditioning status and/or the losing teams' exhibiting low conditioning in defense (Ibanez S. , Garcia, Feu, Lorenzo, \& Sampaio, 2009). Lebih spesifik lagi dijelaskan bahwa tim pemenang pertandingan menunjukkan performa yang lebih baik dalam pertahanan daripada tim yang kalah.

Berbeda dengan dua penelitian tersebut diketahui ternyata dalam beberapa pertandingan dapat terjadi tim pemenang pertandingan memiliki persentase keberhasilan tembakan yang lebih rendah daripada lawannya. Dalam kondisi khusus seperti ini tentunya terdapat indikator performa lainnya yang mempengaruhi kemenangan sebuah tim dalam pertandingan bola basket. Tim pemenang dengan persentase tembakan lebih randah daripada lawan memiliki perbedaan rata-rata indikator performa lebih tinggi dalam offensive efficiency, three point field goal made, free throw made, offensive rebound dan steal, sedangkan tim kalah memiliki rata-rata indikator performa lebih tinggi dalam turnover dan foul (Hidayatullah, 2012).

Melalui berbagai penelitian sebelumnya tersebut sudah nampak bahwa 


\begin{tabular}{|c|c|}
\hline Journal STAND: Sports and Development \\
unipa Sumalama
\end{tabular} $\begin{gathered}\text { htt//jurnal.unipasby.ac.id/index.php/stand/about/submissions } \\
\text { jurnal.stand@unipasby.ac.id }\end{gathered}$

indikator performa bola basket yang

signifikan membedakan antara tim berhubungan dengan kemampuan dalam menyerang selalu menjadi pengaruh utama yang membedakan antara tim pemenang dan tim yang kalah. Namun perlu dicermati lebih lanjut secara terpisah dalam menganalisis performa serangan tim yang mana yang paling besar mempengaruhi kemenangan sebuah tim pelajar bola basket di Kabuapten Bangkalan. Hal ini menjadi menarik untuk dibahas apakah banyaknya serangan yang dilakukan sebuah tim juga berpengaruh dalam membedakan tim pemenang dan tim yang kalah. Dalam penelitian terakhir yang dilakukan peneliti ditemukan bahwa tembakan 3 angka yang masuk dari tim pemenang pertandingan menunjukkan angka yang lebih baik daripada tim yang kalah. Dalam penelitian ini jumlah serangan sebuah tim akan diwakili oleh Three Point Attempt dan Free Throw Attempt serta turnover. Serangan tembakan dua angka dalam hal ini tidak ikut dianalisis karena melihat fenomena dalam penelitian sebelumnya namun dengan hipotesis bahwa semakin banyak serangan tembakan yang dilakukan oleh sebuah tim maka akan meningkatkan peluang kemenangannya. Sedangkan untuk indikator pertahanan yang akan dianalisis adalah rebound, block, steal dan personal foul. Dari ketujuh indikator performa tersebut akan diujikan mana yang

pemenang dan tim yang kalah dalam pertandingan bola basket tingkat pelajar di Kabupaten Bangkalan.

\section{METODE PENELITIAN}

Penelitian ini merupakan penelitian deskriptif yang menggunakan pendekatan kuantitatif dalam mencari jawaban beberapa permasalahan yang ditemukan. Accidental random sampling digunakan sebagai teknik sampling dalam penelitian ini dengan mengumpulkan data pertandingan yang dikumpulkan sendiri oleh penelitia dalam pertandingan bola basket antar pelajar di Kabupaten Bangkalan yang telah berlangsung pada tahun 2019. Dengan dibantu dengan software pencatat statistik pertandingan "Basketball Stats Assistant" data statistik pertandingan dikumpulkan setiap peneliti dapat hadir ke lapangan saat pertandingan. Seluruh pertandingan bola basket tingkat pelajar yang dianalisis dalam penelitian ini sebanyak 36 pertandingan bola basket pelajar kategori putra.

Analisis data dalam penelitian ini akan menggunakan independent sample t-test dengan sebelumnya melalui uji prasyarat berupa uji normalitas dan uji homogenitas. Uji normalitas data dalam penelitian ini menggunakan uji kolmogorov-smirnov sedangkan untuk uji homogenitas digunakan Levane's test of homogenity. Setelah analisis data dilakukan maka akan ditarik kesimpulan variabel mana yang signifikan 


\begin{tabular}{|c|c|}
\hline Journal STAND: Sports and Development \\
unipa Sumalama
\end{tabular} $\begin{gathered}\text { htt//jurnal.unipasby.ac.id/index.php/stand/about/submissions } \\
\text { jurnal.stand@unipasby.ac.id }\end{gathered}$

membedakan tim pemenang pertandingan dan tim yang kalah.

\section{HASIL DAN PEMBAHASAN}

Uji normalitas data penelitian yang diproses dengan SPSS 16 ini menggunakan uji normalitas kolmogorov-smirnov untuk membuktikan bahwa data penelitian telah terdistribusi dengan normal.

Tabel 1. Uji Normalitas data

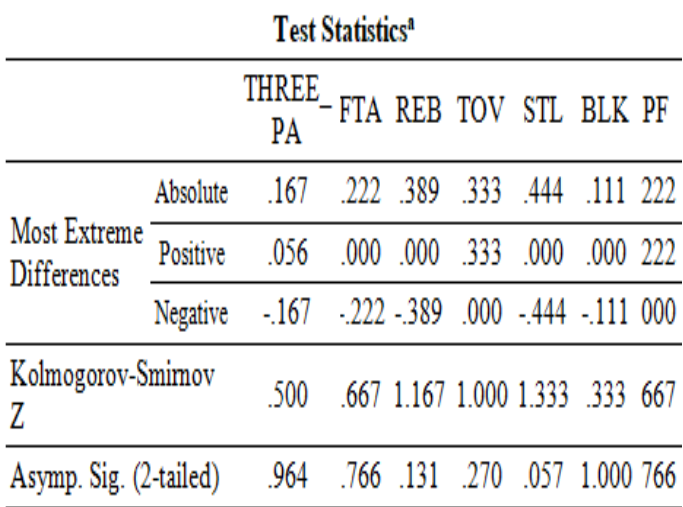

a. Grouping Variable:

Menang_Kalah

Dari hasil uji Kolmogorov-Smirnov pertandingan tim putra diatas dapat diketahui bahwa seluruh variabel dalam penelitian ini telah terdistribusi dengan normal. Tingkat signifikansi seluruh variabel dalam uji Kolmogorov-Smirnov lebih besar dari 0.05 . Setelah data telah dibuktikan terdistribusi dengan normal maka selanjutnya uji homogenitas dilakukan untuk melihat apakah data memiliki homogenitas yang signifikan.

\section{Tabel 2. Uji Homogenitas Data}

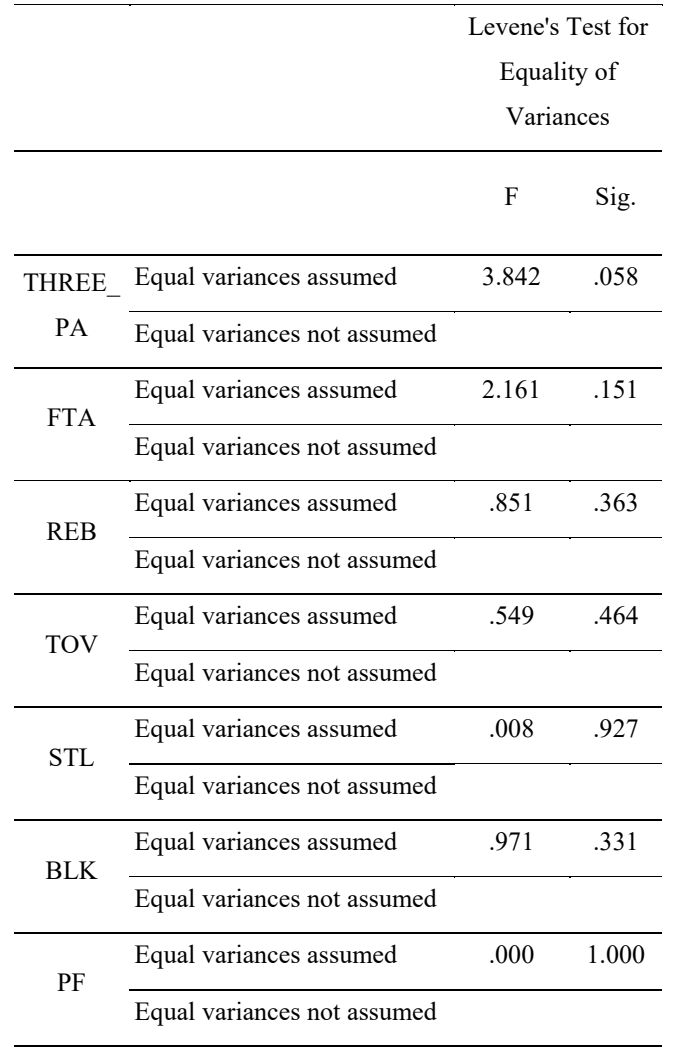

Melalui uji homogenitas dengan Levane's Test dapat dilihat bahwa skor signifikansi setiap variabel menunjukkan angka yang lebih besar dari 0,05 sehingga dapat disimpulkan bahwa seluruh data penelitian memiliki sifat yang homogen yang artinya penggunaan data dapat dilanjutkan pada tahap analisis data dengan independent sample t-test. Dalam melakukan uji analisis data, peneliti menggunakan alat bantu SPSS 16 untuk mempermudah proses pengolahan data. Independent sample t-test adalah uji yang paling tepat digunakan digunakan untuk mengetahui perbedaan statistik pertandingan dari tim 


\begin{tabular}{|c|c|}
\hline Journal STAND: Sports and Development \\
unttp://jurnal.unipasby.ac.id/index.php/stand/about/submissions \\
jurnal.stand@unipasby.ac.id
\end{tabular}

pemenang dan tim yang kalah dalam pertandingan bola basket kategori putra.

Tabel 3. Independent sample t-test

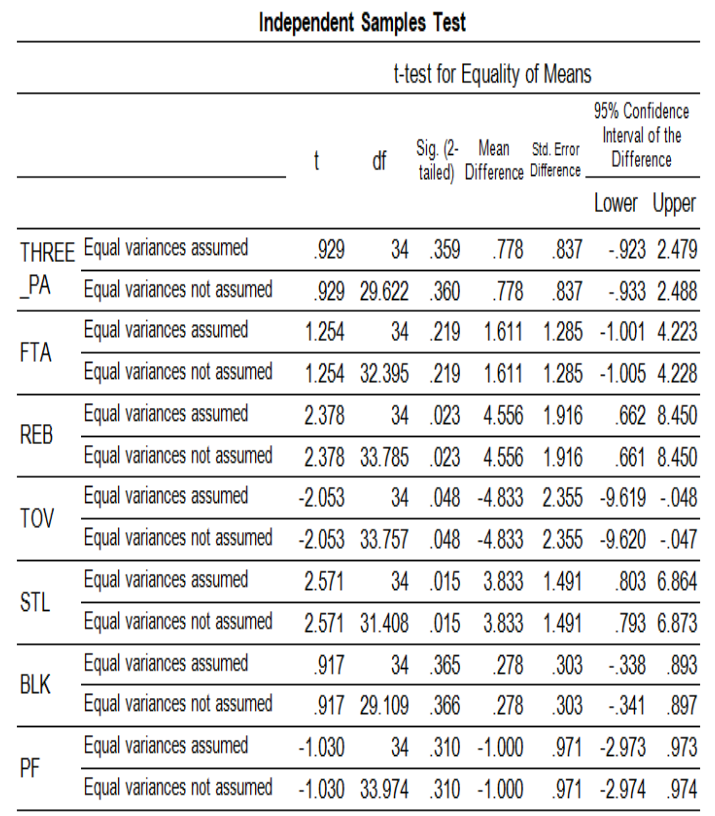

Dari tabel hasil uji independent sample t-test diatas dapat dilihat bahwa nilai signifikansi variabel TOV (Turnover) sebesar 0,048 yang artinya lebih kecil dari 0,05 sehingga dapat disimpulkan bahwa terdapat perbedaan yang signifikan antara tim pemenang dan tim yang kalah pada variabel turnover. Nilai $\mathrm{t}$ yang nampak sebesar -2,053 juga menunjukkan bahwa jumlah mean turnover dari tim pemenang lebih rendah daripada tim yang kalah sehingga kesimpulannya adalah tim pemenang pertandingan banyak memiliki catatan turnover yang lebih sedikit daripada tim yang kalah dalam pertandingan.
Dari tabel diatas pula ditemukan bahwa variabel STL (Steal) ditemukan dengan nilai signifikansi sebesar 0,015 yang artinya lebih kecil daripada nilai signifikansi 0,05 sehingga patut untuk disimpulkan terdapat perbedaan yang signifikan secara statistik antara tim pemenang pertandingan dan tim yang kalah pada catatan variabel steal. Nilai $\mathrm{t}$ yang sebesar 2,571 menunjukkan bahwa tim pemenang disimpulkan memiliki jumlah rata-rata steal yang lebih besar daripada tim kalah.

\section{KESIMPULAN}

Dari hasil analisis diatas dapat disimpulkan bahwa dalam pertandingan bola basket kategori putra, variabel turnover dan steal nampak membedakan antara tim pemenang pertandingan dan tim yang kalah. Kesimpulan dua variabel ini sangat berkaitan erat dikarenakan jika tim pemenang pertandingan banyak melakukan steal maka memang akan sangat mempengaruhi catatan turnover yang dilakukan tim kalah semakin tinggi pula. Hal ini terjadi secara otomatis dimana saat terjadi kejadian steal yang dilakukan oleh salah satu tim bola basket dicatatkan dalam statistik pertandingan maka akan dicatatkan pula turnover pada tim yang kehilangan bola saat terkena steal lawan.

Secara umum dari hasil penelitian ini yang menunjukkan bahwa steal dan turnover menunjukkan perbedaan yang signifikan membuat pemahaman bahwa penguasaan bola 


\begin{tabular}{|c|c|}
\hline unipa Sumalaya & $\begin{array}{c}\text { Journal STAND: Sports and Development } \\
\text { http://jurnal.unipasby.ac.id/index.php/stand/about/submissions } \\
\text { jurnal.stand@unipasby.ac.id }\end{array}$ \\
\hline
\end{tabular}

yang baik dalam pertandingan bola basket sangat penting. Dengan penguasaan bola yang baik, terutama dalam tingkat pelajar sekolah menengah, akan meminimalisir kemungkinan terjadinya turnover yang lebih banyak untuk meningkatkan persentase kemenangan sebuah tim bola basket putra tingkat sekolah menengah di Kabupaten Bangkalan.

\section{REFERENSI}

Bazanov, B. (2007). Integrative Approach Of The Technical And Tactical Aspects In Basketball Coaching. Tallin: Tallin University.

Fylaktakidou, A., Tsamourtzis, E., \& Zaggelidis, G. (2011). The Turnovers Analysis to the Women's National League Basketball Games. Sport Science Review, 20(3), 69 - 83.

Hidayatullah, F. (2012). Analisis Indikator Performa Yang Mempengaruhi Kemenangan Dengan Persentase Tembakan Rendah Dalam National Basketball League Indonesia. Surabaya: Universitas Negeri Surabaya.

Ibanez, S. J., Garcia, J., Feu, S., Lorenzo, A., \& Sampaio, J. (2009). Effects Of Consecutive Basketball Games on The Game-Related Statistics That Discriminate Winner and Losing Teams. Journal Of Sport Science and Medicine, $8,458-462$.

Trninic, S., Dizdar, D., \& Luksic, E. (2002).

Differences Between Winning and Defeated Top Quality Basketball Teams in Final Tournaments of European Club Championship. Original scientific paper, 26, $521-531$. 